\title{
Controlar al capital y redimensionar el derecho de propiedad: propuestas para la ética del desarrollo
}

\author{
JAQUELINE JONGITUD ZAMORA* \\ Centro de Estudios sobre Derecho, Globalización y Seguridad \\ de la Universidad Veracruzana (México) \\ jjongitud@uv.mx
}

\begin{abstract}
Resumen
En este documento, a partir de lo que desde la literatura especializada se registra como los puntos de acuerdo y como los avances en el campo de la teoría ética del desarrollo, se lleva a cabo una descripción de las ventajas y desventajas que se observan en tres mecanismos muy populares como vías para la realización de los postulados de la ética del desarrollo, en especial respecto a aquel que apunta a la necesaria erradicación de la pobreza extrema en el mundo. Una vez realizado el estudio de la Ayuda Oficial para el Desarrollo, la tasa Tobin y la Renta Básica Universal, se analizan las propuestas económica y jurídica, respectivamente, de Thomas Piketty y Luigi Ferrajoli a fin de identificar los aportes teóricos que las mismas pueden realizar al campo de la ética del desarrollo y las ventajas que presentan frente a los mecanismos hasta ahora explorados.
\end{abstract}

Palabras clave: Ética del desarrollo, derechos humanos, ayuda oficial para el desarrollo, tasa Tobin, renta básica universal, capitalismo.

\section{Controlling capital and reshaping the right to property: proposals for development ethics}

\begin{abstract}
In this document, based on what is recorded on the specialized literature as the points of agreement and as the advances in the field of the ethical theory of development, a description is realized on the advantages and disadvantages that can be observed in three mechanisms that are very popular as avenues for the realization of the postulates of development ethics, especially with respect to the one that points to the necessary eradication of extreme poverty in the world. Following the study of the Official Aid for Development, the Tobin tax and the Universal Basic Income, the economic and legal proposals of Thomas Piketty and Luigi Ferrajoli are analyzed in order to identify the theoretical contributions that they can make to the field of development ethics and the advantages they present over the mechanisms explored so far.
\end{abstract}

Key words: Ethics of development, human rights, official development aid, Tobin tax, universal basic income, capitalism.

\footnotetext{
* Doctora en derecho público, docente e investigadora de tiempo completo de la Universidad Veracruzana y miembro del Sistema Nacional de Investigadores de su país. En relación con el tema que desarrolla aquí, ha publicado diversos artículos y los libros: El derecho al desarrollo en el ámbito de las Naciones Unidas. Notas críticas (2008) y La Hidra en educación superior: un caso de estudio (2014). Asimismo, compiló y participó como autora en el libro colectivo Ética del desarrollo y responsabilidad social en el contexto global (2007).
} 


\section{NOTA PRELIMINAR}

En 1848 Marx y Engels (1985: 53-54) desvelaron una constante histórica: la división de los seres humanos en clases explotadas y explotadoras, dominadas y dominantes, oprimidas y poderosas. En el Manifiesto, programa teórico y práctico del comunismo, se vislumbraba (Engels, prefacio de 1883) que la emancipación del proletariado no podría llevarse a cabo sin emancipar al mismo tiempo, y para siempre, a toda la sociedad de la explotación, de la opresión y de las luchas de clases.

Tiempo después las distopías expresan una demoledora crítica no sólo contra el capitalismo (Huxley, 1932; Orwell, 1949) sino también contra el comunismo (Bradbury, 1953), el cual fue retratado en la fábula Rebelión en la granja (Orwell, 1945) que ha sido interpretada como una narración sobre la forma en la que fue pervertido el ideal comunista. Este conjunto de obras no sólo aluden a las consecuencias prácticas de algunas de las ideas base de cada uno de los modelos económicos e ideológicos citados, sino también a diversas concepciones sobre la condición humana.

Tras la conclusión de la Guerra Fría, que dejó tras de sí una larga estela de violaciones a los derechos humanos por el deseo de las potencias rivales de implantar su modelo de gobierno en el mundo (Meyer, 2004); y el anuncio del fin de la historia de Francis Fukuyama (1989: 3-18), con el que se dio por sentado el final de la historia como tal, es decir, con el que se asumió que se había alcanzado el límite de la evolución ideológica de la humanidad así como la universalización de la democracia liberal occidental como la forma definitiva de gobierno y del capitalismo como modelo económico (Hueso, 1998), nos encontramos en un escenario que ofrece más preguntas que respuestas y que exige repensar y replantear temas fundamentales.

En años recientes hemos sido testigos de decisiones democráticas que han causado sorpresa a nivel global: la salida del Reino Unido de la Unión Europea (BREXIT), el no en Colombia al acuerdo de paz con las FARC (Fuerzas Armadas Revolucionarias de Colombia) y la llegada a la presidencia de los Estados Unidos de América de Donald Trump, a través de un discurso racista, xenófobo y misógino. Decisiones que se enmarcan en un contexto global poco alentador y detractor de las promesas del capitalismo y su libre mercado. En efecto, y sólo por citar algunos datos ilustrativos al respecto, este año el Foro Económico Mundial (2017) señaló que la desigualdad económica y de la distribución de la riqueza, el desempleo estructural, la polarización e inestabilidad social y los peligros medioambientales son los principales riesgos que enfrenta la humanidad. 
Oxfam, por su parte, informó apenas el año pasado (2016) que de acuerdo a sus cálculos, de 2010 a 2015 la riqueza en manos de las 62 personas más ricas del mundo se incrementó en un 45\% mientras que la poseída por la mitad más pobre de la población se redujo en un 38\%; en 2016 el 1\% más rico de la población mundial poseía más riqueza que el $99 \%$ del resto del mundo (Oxfam, 2016: 2-3). Es cierto, señala la organización, que entre 1990 y 2010 hubo importantes avances en la reducción del número de personas que viven por debajo del umbral de la pobreza extrema, pero esos logros podrían haber sido mayores en 200 millones de personas si la desigualdad al interior de los países no se hubiese incrementado. Para esta organización es claro que quienes se benefician de la economía mundial son quienes más tienen, pues el sistema económico está cada vez más distorsionado y orientado a favorecerles (Oxfam, 2016: 4).

Tratándose de los derechos humanos a nivel global, Amnistía Internacional (2017: 13-15) destacó que el año 2017 inició con un mundo mucho más inestable y con mucha inquietud e incertidumbre sobre el futuro, siendo además un año en el que dicha organización advierte el riesgo de que los valores que se articulan en la Declaración Universal de los Derechos Humanos (DUDH) no estén ya garantizados. Y es que el 2016 se caracterizó por el deterioro de las libertades civiles y políticas en diversas partes del mundo, además de que la crisis de refugiados en Europa, así como la migratoria a nivel global, y la retórica del odio, la división y la deshumanización como estrategia para alcanzar o conservar el poder han provocado que se dé rienda suelta a la discriminación y a los crímenes de odio, sobre todo en Europa y Estados Unidos, sin dejar pasar por alto por su carácter significativo a Rusia y Filipinas con Vladimir Putin y Rodrigo Duterte.

¿Acaso Schopenhauer (1998: 301) intuía en su tiempo una "verdad" que (aunque ignorada por largo período) finalmente nos está alcanzado?, sobre todo si se toma en cuenta la evidencia científica disponible sobre los peligros medioambientales a los que se enfrenta la humanidad ${ }^{1}$, mismos que han sido minimizados recientemente por los poderes ejecutivos ruso y estadounidense. Schopenhauer afirmaba en El amor, las mujeres y la muerte:

La vida del hombre no es más que una lucha por la existencia, con la certidumbre de resultar vencido... La vida es una cacería incesante, donde los seres, unas veces cazadores y otras cazados, se disputan las piltrafas de una horrible presa. Es una historia natural del dolor, que se resume así: querer

\footnotetext{
1 Entre otros: el aumento del nivel del mar y de la fuerza de los huracanes, las sequías extremas y el aumento en el riesgo de la desertificación de las tierras y el aumento de la temperatura de la tierra que está generando graves daños a la biodiversidad.
} 
sin motivo, sufrir siempre, luchar de continuo y después morir... Y así sucesivamente por los siglos de los siglos, hasta que nuestro planeta se haga trizas.

¿Nos encaminamos a una sexta extinción masiva provocada por la mezcla combustible entre ignorancia y poder de la que habló Carl Sagan (cit. por Valek, 2000: 338)? Una extinción que no tendrá explicación a partir de causas endógenas de la propia biosfera, en la acción de súper volcanes o en el choque de meteoritos contra la tierra. Un final que pudo haber sido evitado, pues desde diversas disciplinas se previó y porque se documentaron las consecuencias que la acción humana estaba generando en el medio ambiente y los efectos que el calentamiento global podía tener sobre el planeta tierra y sus seres vivos. Una extinción que no será registrada y que junto a las previas sencillamente será enterrada en la oscuridad del olvido tras la desaparición del homo sapiens, la especie que había logrado desarrollar las habilidades requeridas para registrar y recrear su propia historia, más allá de la simple memoria biológica.

Si bien no es posible negar la existencia de hechos que simple y llanamente son (Aristóteles, 1998: 74) y sobre los cuales la voluntad humana no tiene papel alguno que jugar -la muerte o un ciclo natural aleatorio-, hay otro conjunto de ellos en los que la inteligencia, la libertad, la voluntad, la creatividad y las capacidades de empatía y solidaridad humanas son sumamente importantes y en los que la adopción de decisiones humanizadoras pueden marcar la diferencia, pues éstas son capaces de generar escenarios distintos a los catastróficos.

Entiendo que el vínculo entre el pasado y la actualidad se cifra en que lo "que somos está determinado por nuestra historia, pero dicha historia no es el correlato de una esencia inmutable... Al contrario, la historia demuestra la indeterminación de las cosas, la futilidad del origen, la historicidad de lo verdadero. La historia nos dice lo que somos, pero lo que somos no remite a lo inmutable sino a lo variable" (Moro, 2006: 157). O, en palabras de Thomas Piketty (2015: 50), "la historia siempre inventa sus propios caminos". En tal contexto, las palabras de Schopenhauer no deben ni pueden ser ignoradas porque su pesimismo parte de la evidente experiencia del dolor y del sufrimiento humano en el mundo, mucho del cual podría ser evitado a partir del reforzamiento o de la recuperación de medios ya explorados por la humanidad y por la invención o creación de nuevos mecanismos, estrategias e instituciones que hagan realidad una justicia global (Pogge, 2013: 51-63).

Todo lo anterior constituye la narración básica en la que considero apropiado presentar algunas reflexiones sobre la ética del desarrollo ya que este campo de estudio atraviesa, entre otros, muchos de los aspectos en 
ella planteados: la desigualdad económica y de la distribución de la riqueza, la pobreza, opresión y explotación, los derechos humanos, el fracaso de modelos de "desarrollo", el medio ambiente, la violencia, la seguridad humana y la paz entre los seres humanos y los pueblos del mundo. Porque pese a todo, como dice Emilio Martínez: "la reflexión ética es una apuesta por la capacidad humana para hacer nuestro mundo... un lugar más habitable, más hospitalario, más humanizado, más desarrollado, en el mejor sentido de la palabra" (Martínez, 2007a: 139).

En el anterior orden de ideas, y dada la complejidad que entraña la cantidad y diversidad de temas involucrados en la ética del desarrollo, mis pretensiones con la elaboración de este escrito son sumamente modestas. En primer lugar, buscaré ofrecer al lector o lectora un acercamiento al objeto de estudio de esta disciplina filosófica, así como un sucinto panorama de lo que desde la literatura experta se reporta como los puntos de acuerdo alcanzados en el ámbito de la teoría ética del desarrollo y sus avances. En segundo término, me detendré en dos propuestas que pienso tienen la capacidad de complementar los significativos adelantos realizados en este campo. Una de tales ideas ha sido elaborada por el economista Thomas Piketty (2015) y la otra por el filósofo del derecho Luigi Ferrajoli (1999); ambas son, a mi juicio, propuestas que proveen ideas valiosas para la materialización del desarrollo concebido desde la perspectiva ética.

2. ESTADO DEL ARTE RESPECTO A LA ÉTICA DEL DESARROLLO: LOS CONSENSOS

Antes he dicho que el escenario global bosquejado exige repensar temas fundamentales. Tal tarea ha sido abordada al menos desde la conclusión de la Segunda Guerra Mundial por la ética del desarrollo que, en términos teóricos y nominales, surgió en la década de los años sesenta del siglo XX. Para ello jugó un importante papel la obra homónima (Ética del Desarrollo) del estadounidense Denis Goulet (1965), quien, como informa la literatura experta (Martínez, 2007b: 363-367 y 2013: 41-43; Crocker: 2004: 1-4), contó con valiosos antecedentes en el trabajo realizado por activistas y críticos sociales, así como en los estudios que desde diversas disciplinas -economía, sociología, antropología- cuestionaron seriamente el modelo de desarrollo implantado tras la conclusión de la Segunda Guerra Mundial.

Desde su configuración como ética aplicada, el interés de la ética del desarrollo ha sido, dicho de forma general, sacar a la luz los valores éticos implicados en los procesos de desarrollo (Cortina, 2011: 10) y ofrecer orientaciones y criterios - personales e institucionales- para que dicho 
desarrollo sea acorde con tales valores y tenga mucho más en cuenta a las personas concretas, sus necesidades y su participación activa para el logro de una vida digna (Martínez, 2007b: 362-363; 2013: 38). En tal sentido, la ética del desarrollo como indica Martínez Navarro (2013: 41) "pretende orientar los comportamientos de las personas involucradas en los asuntos del desarrollo de los pueblos".

A poco más de cincuenta años de contribuciones desde diversas disciplinas y desde diferentes tradiciones éticas, algunos de los teóricos de la ética del desarrollo (Martínez, 2007b; Crocker: 2004 y 2007) se han dado a la tarea de identificar los puntos de acuerdo alcanzados entre los expertos en la materia ${ }^{2}$. Con base en tales estudios cabe decir que entre los doctrinarios se observa cierta armonía en la aceptación de los siguientes aspectos de la ética del desarrollo:

1. Se centra en un concepto de desarrollo (bueno, auténtico, humano, justo, éticamente justificado, sostenible) que no lo confunde con el mero crecimiento económico y con la modernización de una sociedad;

2. Es un campo de estudio interdisciplinar, con componentes teóricos y prácticos, que no elude su condición filosófica y su compromiso con la evaluación moral de lo que debe ser tenido como un buen desarrollo o como un auténtico desarrollo;

3. Tiene una tarea internacional o global en la que la prioridad es comprender y reducir las privaciones y la pobreza extrema en el mundo;

4. Postula la existencia de principios que son relevantes para cualquier comunidad política, pero, a la vez, reconoce que todo proyecto o estrategia de desarrollo debe contextualizarse, y, en tal sentido, atender al pluralismo cultural, de agentes sociales, de realidades, de posibilidades y necesidades;

5. Sostiene que la renta y la riqueza no son un fin en sí mismo, sino sólo un medio para alcanzar el tipo de vida que las personas valoran; $y$,

6. Se desenvuelve en diferentes niveles de generalidad y especificidad, por lo que debe evaluar: a) los principios éticos básicos involucrados en los procesos de desarrollo, como la justicia, la libertad, la autonomía, la solidaridad y la democracia; b) los fines y

2 David Crocker (2004 y 2007) ha identificado diez puntos de acuerdo y Emilio Martínez (2007b) señala al menos ocho. Personalmente y tras el análisis de las propuestas de Denis Goulet, David Crocker, Emilio Martínez y Amartya Sen logré identificar entre ellos seis áreas de consenso (Jongitud, 2003). 
los modelos de desarrollo disponibles y éticamente sostenibles; y c) las instituciones, los proyectos y las estrategias específicas de desarrollo.

Las aportaciones que desde la ética del desarrollo se han hecho han influido de forma positiva y significativa en rubros diversos tales como la recuperación y revitalización de la relación entre ética y economía (Sen, 1999; Conill, 2004); el reconocimiento en el orden internacional del derecho humano al desarrollo, como un derecho que pertenece a todas las personas y a todos los pueblos del mundo (ONU, 1986); y, finalmente, sin que éstos sean los únicos aportes, la comprensión del desarrollo como un proceso integral que involucra diversos niveles (individuales, locales, nacionales, internacionales) y aspectos (sociales, económicos, culturales, políticos y ambientales) que implican, a su vez, la existencia de bienes internos y valores éticos que deben ser atendidos. Esto último también conllevó a la aceptación de la insuficiencia de los conceptos de Producto Interno Bruto (PIB) y de Ingreso Nacional Bruto (INB) como indicadores universales y únicos en la medición del desarrollo de las naciones y a la adopción, por parte del Programa de las Naciones Unidas para el Desarrollo (PNUD), del Índice de Desarrollo Humano (IDH) como medición de los logros por país en dimensiones básicas para el desarrollo humano, como la esperanza de vida al nacer, la salud y la educación.

Dicho lo anterior, sólo cabe destacar que una de las teorías éticas del desarrollo que mejor acogida ha tenido en el campo de los organismos internacionales es la elaborada por el economista Amartya Sen (2000) quien sostiene que el desarrollo puede ser concebido como un proceso de expansión de las libertades reales de las que disfruta la gente (desarrollo humano). De tal forma que el desarrollo es una progresiva ampliación de las capacidades humanas que le permite a las personas gozar de la libertad suficiente para elegir y llevar a cabo aquellos proyectos de vida que consideran valiosos (Martínez, 2013: 48-50). La propuesta del desarrollo como libertad de Amartya Sen (2000) coincide con todos y cada uno de los puntos que antes he señalado como los acuerdos alcanzados en el ámbito especializado de la ética del desarrollo y está íntimamente relacionada con los avances en el campo de la medición del desarrollo de los países, pues el IDH del PNUD se basa en dicho enfoque.

El estado de las cosas en el ámbito de la ética del desarrollo y los acuerdos y logros tanto en el ámbito teórico como en el de la incidencia concreta en las políticas de desarrollo, contrasta duramente con el escenario global actual, plagado de discursos y prácticas deshumanizantes, una tremenda desigualdad y concentración de la riqueza y una retracción en la garantía de los derechos civiles y políticos, así como de los económicos, 
sociales y culturales, a lo largo del planeta. Todo lo anterior no trastoca, lógicamente, el carácter normativo y de deseabilidad de los postulados básicos emanados de la ética del desarrollo.

3. MEDIDAS PARA ALCANZAR LOS POSTULAdos DE LA ÉTICA DEL DESARROLLO

A lo largo de la evolución de la ética del desarrollo, además de lo expuesto en el apartado anterior y de la identificación, documentación y denuncia de las malas prácticas de los gobiernos y de las organizaciones internacionales en sus relaciones con los países empobrecidos (Martínez, 2013: 46-47), se han realizado propuestas creativas y útiles para hacer efectivos los bienes internos, los principios y los valores éticos implicados en los procesos de desarrollo y para reducir las privaciones y la pobreza extrema en el mundo. Ejemplos bastante conocidos de lo anterior son la instauración de la Ayuda Oficial para el Desarrollo (AOD) ${ }^{3}$, la tasa Tobin y la Renta Básica Universal, a las cuales me referiré brevemente para posteriormente engarzarlas con las propuestas de Thomas Piketty (2015) y Luigi Ferrajoli (1999), tal como lo anuncié en la nota preliminar de este documento.

La AOD se instauró como un compromiso de los países económicamente más adelantados en el Segundo Decenio de las Naciones Unidas para el Desarrollo (ONU, 1970) con el objetivo de crear un nuevo orden económico internacional (ONU, 1974) que corrigiera las desigualdades, reparara las injusticias y eliminara las asimetrías entre los países desarrollados y los países en desarrollo, de tal forma que se garantizara un desarrollo económico y social, en la paz y la justicia.

La AOD debía alcanzar a la mitad de los años setenta una cantidad neta mínima equivalente al 0,7\% del Producto Nacional Bruto de los países más ricos. No obstante, esta meta sólo ha sido alcanzada por Suecia, Noruega, Dinamarca, Luxemburgo, el Reino Unido y los Países Bajos. Según datos del Banco Mundial (BM, 2017) el año con mayor flujo de recursos fue 1975 con 0,315\% y el más crítico fue el 2012 en el que el flujo de ayuda fue de apenas $0,178 \%$, montos aún por debajo de los registrados en años previos a la asunción del compromiso internacional; en efecto, entre 1961 y 1965 la AOD registró flujos, respectivamente, del 0,367\%, 0,350\%, $0,358 \%, 0,327 \%$ y $0,321 \%$.

3 Se constituye por los gastos netos de créditos (en condiciones financieras favorables) y donaciones, realizados por países ricos con el objetivo primordial de apoyar el desarrollo económico y social de los países receptores de ayuda. 
Desde sus orígenes el papel de la AOD ha estado en el campo del debate, pues mientras hay quienes consideran que ésta es necesaria para promover e impulsar el desarrollo de los países pobres, además de que contribuye a frenar el proceso de acumulación del capital y el aumento de las rentas familiares; otros sostienen, en cambio, que la AOD ha sido ineficaz y contribuye de forma negativa en los países receptores (Maroto, 2014: 161; Rodríguez, et al., 2013: 111), pues en los últimos cincuenta años han llegado a los países en desarrollo más de tres trillones de dólares, sin que el objetivo central para el que fue creada se haya cumplido ya que dichos países aún no logran salir de la pobreza (Rodríguez, et al., 2013: 111).

En contra de lo anterior se argumenta que la AOD es insuficiente para aliviar los graves desequilibrios generados por el actual orden económico mundial; que su condicionamiento, falta de atención a las necesidades y al contexto de los países receptores y su uso político en asuntos exteriores y comerciales han limitado su eficacia; que algunos de los gastos que se presentan como ayuda para el desarrollo no se traducen en una transferencia real de recursos a los países en desarrollo (Concord AidWarch, 2015) y que por cada dólar de AOD las instituciones bancarias obtienen tres en pago de intereses, por lo que los países pobres acaban pagando a los países ricos más de lo que reciben en ayuda (Social Watch, 2007).

La significativa reducción del monto disponible de AOD y el cuestionamiento sobre su eficacia ha dado pie a que algunos especialistas (Muñoz y Torres, 2012: 1046) hablen de que ésta se encuentra en un momento crítico que exige de una mejor orientación geográfica y sectorial, de tal forma que la disminución de la cuantía sea compensada por una mejor asignación.

Por otra parte, la tasa Tobin es un impuesto sobre transacciones financieras (propuesto por James Tobin, en 1971) aplicable en un monto de entre 0.1 y $0.5 \%$ a todas las compras de instrumentos financieros denominados en otra divisa (desde divisa y moneda, hasta títulos sobre activos). Es un impuesto dirigido a combatir la especulación financiera mundial y cuyo capital recolectado podría ser aplicado en herramientas de cooperación con los países que reciben los mayores perjuicios de la economía de mercado (Alonzo, 2004: 36; Cante y Ramírez, 2011: 254; Pleyers, 2003: 183).

De acuerdo con la propuesta inicial, el impuesto debería ser administrado por cada gobierno y ser uniforme y universal a fin de que el mercado de divisas no evadiera el pago (Allami y Cibils, 2010: 64). Al mismo tiempo, una agencia multilateral como el BM o el FMI (Fondo Monetario Internacional) recaudaría el impuesto y controlaría a las autoridades regulatorias nacionales. 
La tasa Tobin o análogas en su tipo han sido implantadas en Suecia y el Reino Unido. En Suecia la tasa se implantó en 1984, pero fue abandonada completamente a finales de 1991 porque la recaudación no fue la esperada, porque decayó el volumen de negocios imponibles y porque los precios accionarios también decayeron incrementando el coste del endeudamiento público. En el Reino Unido con antelación a la propuesta de la tasa Tobin se habían venido aplicando dos tasas sobre transacciones financieras: la Stamp Duty Reserve Tax y el impuesto de sello (desde 1808), ambas fueron objeto de una reducción gradual pasando la primera de un $2 \%$ original hasta el $0.5 \%$ actualmente vigente y la segunda de un $2 \%$ a un $1 \%$ ante la evidencia empírica de que la reducción conducía a un incremento en el volumen de valores y a rendimientos más positivos en la bolsa de valores de Londres. En la Unión Europea el tema de un impuesto sobre las transacciones financieras se ha discutido al menos desde el año 2011, alcanzándose un punto de acuerdo, con la oposición del Reino Unido y Suecia (Vidal, 2014b), para ponerla en marcha el primero de enero de 2016, sin embargo, llegada la fecha señalada se aplazó su adopción para el año 2017 (Estefanía, 2016; Valero, 2017).

Por último, la Renta Básica Universal (propuesta por el filósofo Philippe van Parijs, en 1995) puede ser entendida como un ingreso monetario periódico, irrenunciable y suficiente para satisfacer las necesidades básicas, que es garantizada por el Estado a todas las personas sujetas a su jurisdicción, con independencia de su situación personal y sin condicionamiento alguno (Alcalá, 2009: 83-86; Hevia, 2011: 350).

A favor de la Renta Básica Universal se dice que permite cumplir con la noción de libertad como no dominación, es decir, como la consecusión de una libertad real para la toma de decisiones; que contando con ella nadie se vería obligado a aceptar cualquier tipo de trabajo para sobrevivir con un mínimo de dignidad y que permitiría la sustitución de un sinnúmero de programas sociales, junto con sus costosas burocracias y abigarrados trámites; que coadyuvaría con la distribución de la riqueza, la reducción de la pobreza y la mejora de la situación de las personas con un poder adquisitivo bajo (Alcalá, 2009:86; Castrillón, 2016: 349); que brindaría el mínimo social indispensable para la protección de los derechos humanos (Hevia, 2011: 350); y que permitiría hacer frente a los cambios estructurales que la tecnología provocará en la economía global y que dejará sin oportunidades de empleo a una parte importante de la población mundial (Llinares, 2017). A todo esto se suma que podría abonar en pro de la seguridad y de la paz, en la medida en la que tiene la capacidad de quitar presión al conflicto social generado por la falta de empleo y por las limitaciones en el acceso a los bienes más elementales para la subsistencia de las personas. 
Los detractores, por su parte, afirman que desalentaría el empleo y que supondría un gasto que reduciría la inversión en programas que han probado su eficacia para promover la igualdad de oportunidades, como por ejemplo la educación pública; que conllevaría la utilización de recursos que podrían ser utilizados para generar empleo y atraer inversiones; que generaría inflación creciente hasta anular el valor real del dinero obtenido a través de la Renta Básica Universal; y, que atraería a un gran número de inmigrantes que buscarían conseguir la renta sin contribuir en actividades productivas.

Actualmente Finlandia y Holanda están llevando a cabo testeos de la medida en grupos pilotos a fin de ver los efectos de la misma sobre sus ciudadanos y para tomar una decisión definitiva sobre su aplicación a toda la población (Llinares, 2017).

Cada una de las medidas abordadas tiene un importante potencial como vía para la realización del desarrollo (desarrollo bumano), pero, a la vez, muestra limitaciones importantes. Como se ha visto, la AOD podría liberar recursos significativos para atender a las necesidades de desarrollo de los países más pobres; sin embargo, descansa en una serie de factores que han limitado de forma significativa su eficacia: depende de la voluntad de los países donantes y, por ende, se ha ligado en primer término a sus propios intereses y no al de las necesidades de los países receptores; se le ha tendido a observar como un acto de asistencia, de caridad (no hay que olvidar que la mano que da, siempre está arriba, y la que recibe, abajo), y no como un acto de justicia frente al colonialismo depredador y a las desigualdades históricas que generó, las cuales se siguieron perpetuando a partir de la imposición de un modelo de desarrollo economicista; y, aun cuando a partir de la década de los noventa se le empezó a orientar en el sentido de que por lo menos una parte de esa ayuda se dirigiese a la erradicación de la pobreza mediante la cobertura de necesidades básicas de la población de los países menos adelantados (Muñoz y Torres, 2012), la disponibilidad de recursos ha disminuido de forma significativa en un contexto en el que la riqueza pública ha perdido terreno frente a la riqueza privada.

La tasa Tobin, por su parte, es capaz de frenar la especulación financiera y lograr una mayor estabilidad en los mercados internacionales de divisas, además de que podría ser un valioso instrumento para incentivar la transferencia de recursos de la economía financiera a la economía real (Conill, 2004: 229-230) y ser un mecanismo que permita hacer transparentes las operaciones financieras internacionales, cuanto y más atendiendo a la relación que se ha establecido entre la especulación financiera y las crisis económicas. No obstante, como se ha observado antes, la tasa Tobin ha 
tenido problemas en su adopción. Quizá, como señala la literatura especializada (Allami y Cibils, 2010: 66-67), esto obedezca a que para que la imposición de la tasa sea exitosa se requiere que su adopción sea uniforme y universal, esto es, que fuese adoptada de forma simultánea por parte de todos los países, ya que de no ser así se generaría un flujo masivo de capitales hacia aquellos países que no la hayan adoptado, generando por ello un perjuicio mayor a los beneficios esperados por parte de las naciones que la establezcan. Adicionalmente, la tasa Tobin enfrenta dificultades en torno a su monitoreo y a la necesidad de que sea una organización supranacional la que supervise la recolección y la distribución del impuesto. A ello se une la ausencia de mecanismos que eviten la huida o el desvío de capitales, como hasta el momento acontece, hacia los paraísos fiscales.

Finalmente, la instauración de la Renta Básica Universal sería una medida potente y efectiva para combatir la pobreza y para erradicar las privaciones de lo más elemental para la vida de las personas, pero su implementación depende de factores muy diversos, como por ejemplo la situación económica del Estado que haya de aplicarla, su grado de autosuficiencia económica y la disponibilidad de recursos. En los países más adelantados económicamente quizá la medida sea técnica y económicamente viable, pero habrá países, los más empobrecidos, en los que la misma no sea ni siquiera imaginable.

Las propuestas señaladas guardan entre sí puntos en común: todas se encaminan a la búsqueda de recursos, todas proponen la liberalización de los mismos desde diferentes fuentes (los países más ricos, la imposición a transferencias financieras o los recursos públicos estatales) y todas se dirigen de una u otra forma a fomentar los procesos de desarrollo nacionales y a paliar la desigualdad económica y social en diversos niveles: entre países o al interior de ellos.

A mi juicio, este conjunto de medidas tratan de actuar sobre los resultados generados por un sistema económico: el capitalismo. Intentan aliviar algunas de sus cargas y efectos a través de la redistribución de los bienes, sin atender a sus causas (Cante y Ramírez, 2011: 254). Si bien es cierto que no es posible hablar de un "capitalismo" sino de "capitalismos" con perfiles distinguibles entre sí (Giraldi, 1995; Conill, 2004: 233-234), lo concreto es que durante las últimas décadas del siglo pasado se asistió a la creciente financiarización de la economía mundial y a la hegemonía del modelo de capitalismo en el que se valora por sobre todo la competencia y el enriquecimiento individual, así como los beneficios de tipo cortoplacista; un capitalismo en el que lo esencial es el desempeño financiero de las inversiones, el rendimiento de los títulos que las representan y no las actividades productivas o el bienestar social (Archel y Gómez, 2014: 105107). 
En atención de lo anterior considero que es necesario ir mucho más allá de las propuestas revisadas y de las análogas a ellas. A mi juicio, deben atajarse de forma radical algunos aspectos de la lógica capitalista dominante y para ello considero que las propuestas de Thomas Piketty (2015) y Luigi Ferrajoli (1999) nos proveen de elementos teóricos que pueden ayudar a pensar mejor las formas o mecanismos que pueden ser de utilidad para hacer frente al escenario actual.

\section{El CAPITAL EN EL SIGLO XXI, ThOMAS PIKETTYY}

Thomas Piketty en el Capital en el Siglo XXI (2015), muestra que la distribución de la riqueza no es el resultado de condiciones técnico-científicas sino de arreglos institucionales, normativos y de diversas formas o modelos de interacción social. No está de acuerdo con la expresión "ciencia económica" y prefiere la denominación "economía política" que tiene el mérito de apuntar hacia la especificidad de la economía dentro del campo de las ciencias sociales, es decir, hacia su intención política, normativa y moral, pues desde sus orígenes esta área del conocimiento ha intentado estudiar "... cuando menos racionalmente, y de forma sistemática y metódica, cuál debe ser el papel ideal del Estado en la organización económica y social de un país, cuáles son las instituciones y políticas públicas que más nos acercan a una sociedad ideal" (Piketty, 2015: 645-646).

A través de estudios empíricos (casos de aplicación de decisiones económicas) y estadísticos Piketty analiza la dinámica global de la distribución de los ingresos y de la riqueza desde el siglo XVIII y hasta inicios del siglo XXI, con datos de más de 20 países, y muestra que hay una tendencia a largo plazo no a la reducción de la desigualdad -como se sostuvo a partir de los estudios de Kuznets- sino a su aumento. Él indica que la primera regularidad observada en la medición de la desigualdad en los ingresos, es que la desigualdad respecto al capital siempre es mucho mayor que la del trabajo, y que la distribución de la propiedad del capital y de los ingresos resultantes de éste es sistemáticamente más concentrada que la de los ingresos del trabajo. Esta regularidad la observó en todos los países y en todas las épocas para las que Piketty (2015: 267) contó con datos, sin ninguna excepción, y cada vez de manera más marcada. La riqueza se concentra extraordinariamente en el décil más rico y dentro de este décil más rico el 1\% tiende a tener una concentración todavía mayor y dentro de éste el $0.1 \%$ concentra todavía más y dentro de éste el $0.01 \%$ todavía más, la tendencia es pues a una mayor concentración de la riqueza (Piketty, 2015: 269-274), tal como se observó con los datos de Oxfam citados en la nota preliminar de este escrito, de acuerdo con los cuales el 1\% más rico de la población mundial posee más riqueza que el 99\% del resto del mundo. 
Esta tendencia expresa un retorno al capitalismo patrimonialista del siglo XIX, oligárquico, plutocrático y no democrático, que representa un enorme peligro porque el poder económico se traduce en un gran poder político, que se vuelve sumamente difícil de controlar, pero esta tendencia es una construcción social como muchas otras que explora Piketty en su libro y, por ende, puede deconstruirse socialmente. De ahí que el autor proponga la difusión de la educación y la inversión en conocimiento como mecanismos decisivos para la reducción de las desigualdades, además de proponer democratizar la riqueza a partir de la introducción de un impuesto progresivo anual sobre el capital (Piketty, 2015: 643-645) que permita contener el crecimiento de las desigualdades patrimoniales mundiales que están incrementándose de forma insostenible a largo plazo, pero que, a un mismo tiempo, sea capaz de preservar las fuerzas de la competencia y los incentivos para las acumulaciones originarias. En este sentido, en una entrevista realizada por Xavier Vidal (2014a), Piketty afirmaba que estamos en un período histórico en el que las grandes fortunas crecen anualmente entre un $6 \%$ y un $8 \%$ por lo que un impuesto de un $1 \%$, no sería confiscatorio ni mucho menos.

La propuesta, como admite Pikkety, se enfrenta a las dificultades de requerir un muy alto grado de cooperación internacional y de integración política regional. Así, su propuesta parece estar en el mismo lugar que la AOD, la tasa Tobin, y la Renta Básica Universal, pues al igual que ellas presenta oportunidades y limitaciones, empezando por la difícil convergencia entre todos y cada uno de los países del globo y, sobre todo, de aquellos que concentran o alojan las mayores cantidades de capital. En su descargo, Piketty argumenta que su propuesta no inventa nada en el vacío y que parte del hecho de que la mayor parte de los países del mundo han instaurado impuestos sobre la propiedad inmobiliaria por lo que sólo es necesario modernizar el esquema y transformar esos impuestos en un impuesto progresivo y global, que grave todos los distintos activos patrimoniales netos, puesto que se han diversificado, lo cual permitiría aligerar la carga impositiva a una mayoría de la población y hacer transparente la acumulación de capitales (Vidal, 2014a). En este contexto Piketty considera que su propuesta es técnicamente más factible y sencilla que la tasa Tobin.

Más allá de lo anterior, a mi juicio, lo que resulta de más interés en la obra de Piketty para la ética del desarrollo son tres aspectos. En primer término, la demostración estadística de la invalidez de la teoría de la "curva de Kuznets", según la cual a una fase de crecimiento natural de la desigualdad (característica de las primeras etapas de la industrialización) seguiría una fase de fuerte disminución de la misma, lo que implica, a su vez, la derrota del supuesto teórico sobre el cual descansaron las reformas neoli- 
berales a nivel global de las últimas décadas. En segundo lugar, la recuperación de modelos y diseños institucionales utilizados a lo largo de la historia para hacer frente a la desigualdad y para distribuir la riqueza, lo que permite observar la diversidad de esquemas y de los resultados obtenidos a partir de los mismos, abonando con ello en pro del carácter social de la economía y, por ende, de su naturaleza como conocimiento práctico (Aristóteles, 1998: 74-75). Por último, pero no por ello de menor importancia, la identificación de uno de los orígenes de la desigualdad y de la gradación que es posible establecer entre ésta y la pobreza, demostrando que en cierta medida en los tiempos que vivimos el origen puede ser también destino y que el pasado tiende a devorar el porvenir (Piketty, 2015: 415). De esto pareciera desprenderse la idea de que la verdadera desigualdad está en la distribución de la riqueza, por lo que el problema central no es tanto la pobreza, sino la desigualdad, la cual, como dice el mismo Piketty (2015: 34) no es necesariamente mala en sí: el tema central es saber si se justifica, si tiene razones de ser. El problema es que hoy día, en muchos países del mundo, recorre la idea de que las desigualdades de las riquezas no responden necesariamente a las ideas democráticas del mérito, el talento, el trabajo y el esfuerzo, sino a temas como, entre otros, la corrupción, la especulación financiera internacional, la tremenda y artificiosa desigualdad salarial, la depredación homicida y suicida de los recursos naturales de los países empobrecidos y la herencia de grandes capitales.

Hasta aquí las ideas que deseo destacar de Piketty, volveré de nuevo a ellas una vez realizada la exposición de las aportaciones que considero relevantes de Luigi Ferrajoli.

\section{LOS DERECHOS FUNDAMENTALES, LUIGI FERRAJOLI}

Ferrajoli en sus obras Derechos y garantías (1999) y Los fundamentos de los derechos fundamentales (2001) propone una definición teórica, formal o estructural y neutral de los derechos fundamentales ${ }^{4}$ (Ferrajoli, 1999: 35-41), misma que le permite fundar cuatro tesis que, en su opinión, son esenciales para una teoría de la democracia constitucional. De tales tesis me interesa presentar solamente una, la relativa a la radical diferencia de estructura entre los derechos fundamentales y los derechos patrimoniales.

Ferrajoli explica (1999: 45-50) que la confusión entre los derechos fundamentales y los derechos patrimoniales tiene su origen en el Segundo

En este contexto los derechos fundamentales pueden ser entendidos como equivalentes a los derechos humanos. 
tratado sobre el gobierno de John Locke ${ }^{5}$, texto en el que el filósofo identificó a los derechos a la vida, la libertad y la propiedad como fundamentales y como sustento del contrato social. Esta asociación de derechos (de libertad y de propiedad) como parte de una misma categoría se integró en el artículo $2^{\circ}$ de la Declaración de los derechos del hombre y del ciudadano de 1789 y fue retomada en 1852 por Karl Gerber, quien en un estudio sobre los derechos públicos afirmó que tales derechos radicaban no en la esfera jurídica del individuo, sino en la existencia abstracta de la ley, tesis que se extendió y que pronto dominó la doctrina del derecho público (Ferrajoli, 1999: 43-44), pero que es contraria al prius lógico y axiológico, fundante y no fundado, de los derechos fundamentales frente al Estado y al paradigma constitucional de que la positivización de tales derechos crea vínculos y límites al conjunto de los poderes públicos. Poderes que en estricto sentido obtienen su legitimidad en los derechos fundamentales y no a la inversa.

El equívoco se dio, según expone Ferrajoli, por la yuxtaposición de teorías (iusnaturalistas y de tradición civilista y romanista) y por la polisemia de la noción "derecho de propiedad", con la que se entiende al mismo tiempo, por un lado, el derecho a ser propietario y a disponer de los propios derechos de propiedad (capacidad jurídica-capacidad de obrar-derechos civiles) y, por otro, el concreto derecho de propiedad sobre algún bien.

En tal tenor Ferrajoli procede a deshacer la mezcla generada entre los derechos fundamentales y los derechos patrimoniales (1999: 45-50) y a denunciar que la confusión o yuxtaposición de tales derechos fue un grave equívoco teórico del que fue responsable el primer liberalismo, lo que permitió una serie de maniobras políticas durante los siglos XIX y XX que llevaron a equiparar al mismo nivel, dentro de la tradición liberal, el derecho de propiedad con los de libertad, y a la inversa, lo que, a su vez, condicionó hasta nuestros días la teoría de los derechos en su conjunto, y con ella, la del Estado de Derecho. En este mismo sentido, Aguilera y López (2007: 57-58) han sostenido que el descubrimiento de vastos territorios en América del Norte y las expectativas que generó coadyuvaron para que el sentimiento de propiedad predominante en la época fuese interpretado como un derecho no enajenable.

Entonces según Luigi Ferrajoli ¿Cuáles son las diferencias estructurales entre los derechos fundamentales y los derechos patrimoniales? Muy esquemáticamente dicho, las diferencias consisten en que:

5 John Locke concebía el derecho a la propiedad privada como un derecho fundamental que se basaba en el esfuerzo y el trabajo del ser humano sobre la naturaleza. 
a. Mientras los derechos fundamentales (derechos de libertad, políticos, sociales y civiles, incluidos en los últimos los de adquirir y disponer de bienes objeto de propiedad) son universales, es decir, pertenecen a todas las personas; los patrimoniales (derecho de propiedad, derechos reales ${ }^{6}$ y de crédito $^{7}$ ) son derechos singulares para los cuales siempre existe un titular determinado. Así, cuando se habla del derecho de propiedad como un derecho civil se alude a los derechos a convertirse en propietario y a disponer de los bienes que son de nuestra propiedad, es decir, a derechos fundamentales porque conciernen a todos, en el primer caso como personas y en el segundo como capaces de obrar. Pero estos derechos civiles (de carácter universal) son completamente diferentes a los derechos reales sobre bienes determinados, adquiridos o alienados gracias a ellos.

b. Los derechos fundamentales son indisponibles, inalienables, inviolables, intransigibles y personalísimos; los derechos patrimoniales, en cambio, son disponibles por su naturaleza, negociables y alienables. Y, en este último sentido, son susceptibles de limitación (servidumbres administrativas, ocupación temporal...) o de expropiación ya sea por su función social o por causas de utilidad pública.

c. Los derechos fundamentales son normas en sí, los derechos patrimoniales, en cambio, son predispuestos por normas; con esto se refiere a que mientras los primeros se identifican inmediatamente con las normas que los atribuyen; los segundos son siempre actuaciones singulares dispuestas por actos también singulares y predispuestas por normas que los prevén como sus efectos. Por ejemplo: la propiedad de un vestido no es dispuesta como norma sino predispuesta como un efecto dispuesto por la figura jurídica de compraventa, a diferencia de la libertad de manifestación del pensamiento que es dispuesta de forma directa por la mayoría de las constituciones contemporáneas (Ferrajoli, 1999: 45-50).

d. Los derechos patrimoniales son horizontales y los fundamentales son verticales, con esto se apunta a que las relaciones que se entablan dentro de los primeros son intersubjetivas; mientras que

\footnotetext{
6 Los derechos reales son derechos que implican facultades o potestades de la persona sobre las cosas, son ejemplos de éstos, entre otros: la posesión, el usufructo, la habitación, la prenda y la hipoteca.

Son derechos relativos a uno o varios sujetos, como por ejemplo el derecho que tiene el acreedor frente al deudor o el vendedor frente al comprador y viceversa.
} 
los segundos suponen relaciones entre los titulares de los derechos y el Estado. A los primeros corresponden prohibiciones de no lesión o deberes u obligaciones a cargo de los particulares, a los segundos, en cambio, prohibiciones y obligaciones a cargo del Estado cuya violación es causa de invalidez de las leyes y de las decisiones públicas, y cuya observancia es condición para la legitimidad de los poderes públicos.

De los caracteres de los derechos fundamentales derivan vínculos sustanciales normativamente impuestos que obligan tanto a la garantía de las necesidades vitales de todos los seres humanos (derechos fundamentales: vida, libertad, subsistencia, entre otros) como a su sustracción y protección respecto a los intereses del mercado y de las decisiones de la mayoría. Son derechos que se afirman siempre como leyes del más débil en alternativa a la ley del más fuerte que regía y que regirá, sin duda alguna, en su ausencia (Ferrajoli, 1999: 51-54).

De los caracteres de los derechos fundamentales y de su distinción de los patrimoniales emerge otra cuestión de interés, que es el reconocimiento de que el derecho a la propiedad, en su talante de derecho fundamental de tipo civil, es reconocido en sus vertientes individual y colectiva y protegido contra la privación arbitraria (tal como lo establece el artículo 17 de la DUDH), pero es también limitado por causa de utilidad pública, por interés público, por interés general o social conforme a los diversos instrumentos regionales de protección de los derechos humanos. ${ }^{8}$ Siendo la Convención Americana sobre los Derechos Humanos la que va más allá que cualquier otro instrumento de tal naturaleza al regular el derecho a la propiedad, al determinar que la usura o cualquier otra forma de explotación del hombre por el hombre, como por ejemplo: la esclavitud, la servidumbre y los trabajos forzados; debe ser prohibida por la ley (artículo 21.3).

La recuperación del origen de la equiparación entre los derechos fundamentales y los derechos patrimoniales, así como su distinción por parte de Ferrajoli no es en mi opinión sólo un prurito conceptual. Por el contrario, en el proceso de diferenciación de los derechos, Ferrajoli (1999; 2001) va asentando una serie de elementos clave para la ética del desarrollo, a saber:

8 Puede revisarse al respecto el artículo 1 del primer protocolo adicional al Convenio Europeo de Derechos Humanos; el artículo 21 de la Convención Americana sobre Derechos Humanos y el artículo 14 de la Carta Africana de Derechos Humanos y de los Pueblos. 
1) La conexión entre los derechos fundamentales y la igualdad, que le lleva a proponer un constitucionalismo global que establezca niveles mínimos de subsistencia para las personas de los países menos privilegiados (Aguilera y López, 2007).

2) La conexión entre derechos fundamentales y lo que él denomina democracia sustancial y que conlleva al menos tres aseveraciones:

2.1) la satisfacción de los derechos fundamentales es condición de la convivencia civil y, a la vez, el fundamento del artificio del Estado;

2.2) los derechos fundamentales constituyen una esfera de lo indecidible, por lo que deben asegurarse frente al mercado y a las decisiones de la mayoría; $y$,

2.3) los derechos fundamentales se afirman siempre como leyes del más débil, frente a los micro y macro poderes, públicos y privados, creadores de desigualdades dentro y fuera del Estado.

3) La conexión entre los derechos fundamentales y la paz, que puede observarse al menos en dos dimensiones, por un lado, el aseguramiento y la materialización efectiva de los derechos como vía para el logro de la paz y, por otro, la tutela de los derechos fundamentales como causa del contrato social, cuya violación por parte del soberano legitima la ruptura del pacto y el ejercicio por parte del pueblo del derecho de resistencia.

Hasta aquí los puntos que en mi opinión vale la pena destacar respecto a la perspectiva de Luigi Ferrajoli. Revisaré a continuación con más detalle qué puede recuperarse de él y de Thomas Piketty para la perspectiva ética del desarrollo.

\section{CONTROLAR AL CAPITAL, LIMITAR LA PROPIEDAD}

La lectura conjunta de Piketty y Ferrajoli apunta, en mi opinión, a dos aspectos medulares del desarrollo, desde la perspectiva ética. Por un lado, a la condición de factibilidad para la puesta en marcha de algunos de sus postulados y, por otro, al fundamento normativo para el diseño institucional requerido. Esto necesita ser precisado. Cuando hablo de condición de factibilidad me refiero sólo a la disponibilidad de un mecanismo económica y técnicamente viable que supere algunos de los inconvenientes de la AOD, la tasa Tobin y la Renta Básica Universal. Cuando digo fundamento normativo no me refiero al fundamento ético que se ha abordado desde diversas teorías éticas del desarrollo, sino al jurídico. 
Piketty muestra a la concentración del capital como una constante histórica del capitalismo y como uno de los orígenes de la desigualdad; asimismo, hace patente la necesidad de retomar el control del sistema capitalista (Piketty, 2015: 645). Su propuesta a diferencia de la AOD no descansa en un presupuesto de buena voluntad de los países donantes, de asistencia o de caridad, sino en la demostración de que el crecimiento de las desigualdades patrimoniales es insostenible a largo plazo, que esto genera disfunciones en el mercado y que el no detenerlas contribuye a su perpetuación y a una todavía mayor concentración de capitales, lo que es incompatible con los principios de justicia social, base de las sociedades democráticas (Piketty, 2015: 42).

Frente a la tasa Tobin, la propuesta de Piketty es más completa y ambiciosa porque no sólo plantea gravar las transacciones financieras de compra de instrumentos denominados en otra divisa, sino todos los distintos activos patrimoniales netos, fijando como punto de partida un porcentaje de entre un 0.1 y un $0.5 \%$ que iría avanzando según el grado de concentración de la riqueza, en sus propias palabras:

...hemos mencionado la posibilidad de una lista de tasas impositivas al capital con tasas limitadas a 0.1 o $0.5 \%$ anual sobre los patrimonios de menos de un millón de euros, de 1\% para fortunas entre uno y cinco millones de euros, de 2 a $5 \%$ para aquellas de entre cinco y diez millones de euros, o $10 \%$ anual para las fortunas de varios cientos o miles de millones de euros... (Piketty, 2015: 644).

Adicionalmente, como se señaló en el cuarto apartado, según el autor, se trata de un impuesto en el que diversos Estados del mundo ya cuentan con experiencia, por lo que solamente se requeriría modernizar el esquema y transformar tal impuesto en progresivo y global, que grave todos los distintos activos patrimoniales netos. En este sentido, de lograrse un acuerdo global, que por lo demás es una de las dificultades que es claro que la propuesta de Piketty comparte con la tasa Tobin, podrían generarse recursos que serían sujetos a una distribución equitativa en términos de contribución y de atención a las necesidades humanas básicas; así, la Renta Básica Universal no sería sólo privilegio de los habitantes de los países más ricos, sino una garantía mínima de toda persona, que quitaría impulso a las migraciones masivas que descansan en la búsqueda de alimento, seguridad y cobijo.

Pero, quizá, lo que resulta de mayor relevancia en la propuesta de Piketty para la ética del desarrollo es que demuestra la posibilidad de recuperar recursos para el desarrollo, esto es, no refiere por qué y en qué deben in- 
vertirse los recursos, cuestión sobre la cual la teoría ética del desarrollo ha trabajado seria y profusamente, sino el cómo y a través de qué mecanismo es posible obtenerlos sin que se paralice la inversión, sin que se desincentive la economía y sin que los recursos liberados queden dispuestos a un juego de intereses y en particular, a favor del interés de los detentadores del capital. El problema de la desigualdad global no es pues, a partir de la propuesta de Piketty, un tema técnico-científico-económico, sino político y su resolución habla de la voluntad, conciencia, responsabilidad y capacidad de los actores políticos.

En otro orden de ideas, cabe decir que hasta el momento se han utilizado diferentes vías para vincular lo éticamente justificado (desarrollo: auténtico, humano, justo, éticamente justificado, sostenible, sustentable...) a deberes concretos de los Estados en materia de desarrollo. En este sentido, por ejemplo, el reconocimiento del derecho humano al desarrollo a través de la Declaración sobre el derecho al desarrollo (1986) representó un claro paso en tal dirección y ha ayudado sin duda a que diferentes órganos y organismos de las Naciones Unidas trabajen a partir de una perspectiva mucho más integral y acorde con un enfoque ético del desarrollo, tal como se ha dicho respecto al PNUD; no obstante, la declaración pertenece al campo del soft law y hasta ahora no se ha logrado un acuerdo global que haga plenamente vinculante el derecho al desarrollo.

En tal orden de ideas, de la propuesta de Ferrajoli lo que vale la pena destacar es que si la satisfacción de los derechos fundamentales es el fundamento del artificio conocido como Estado, si los derechos son fundantes del Estado, entonces esto: lo fundante debe respetarse, protegerse y garantizarse en cualquier orden ulterior generado por ellos. Esto lleva a observar dos cosas, por un lado, que en el orden internacional existe un marcado desequilibrio entre la regulación y el aseguramiento de los intereses de carácter económico y sus equivalentes en materia de derechos humanos, desigualdad que incluso puede implicar un atentado contra los derechos fundamentales, en especial de las poblaciones de los países más pobres (Jongitud, 2010: 119-135), lo que conlleva, en términos teóricos, a calificar como espurio todo acuerdo entre Estados que desatienda a este principio constitutivo planteado por Ferrajoli. A este respecto Pogge resulta muy persuasivo, cuanto expone:

Consideremos, por ejemplo, un contrato de larga duración respecto de la explotación de recursos naturales que el gobierno de un país africano firma con un rico Estado occidental o con alguna de sus corporaciones. Dentro del marco filosófico tradicional, resulta evidente que un acuerdo de este tipo debe ser cumplido: 'Los pueblos deben cumplir los tratados y acuerdos', afirma el segundo principio de Rawls para la conducta de los Estados, y el 
tercero añade: 'Los pueblos son iguales y se erigen en partes de los acuerdos que los vinculan' (Rawls 1999). Pero la realidad es ésta: el gobierno africano es corrupto y opresivo y su continuidad en el poder depende en gran medida del ejército; las ventas que lleva a cabo imponen daños medioambientales y riesgos sobre la población indígena; además, la mayoría de esta población no recibe beneficio alguno porque en parte se desvían en provecho de la reducida elite política, y en parte se destinan a la compra del armamento necesario para la represión militar. (Estas armas son suministradas por otros países ricos de acuerdo con otros contratos cumplidos, sin coerción, entre ellos y el gobierno africano) (Pogge, 2013: 55-56).

Por otro lado, cabe observar que, de acuerdo con la propuesta de Ferrajoli, la valoración del orden internacional podría darse incluso antes de la interpretación y aplicación de las reglas que el propio orden internacional provee para su evaluación, como por ejemplo el artículo 28 de la DUDH como lo ha propuesto Pogge (2013: 51-109), las normas relativas al derecho de los pueblos y de las personas al desarrollo o, incluso, las cartas constitutivas de organismos internacionales como la Organización Mundial del Comercio, el BM o el FMI (Jongitud, 2008: 101), pues cualquier acuerdo entre Estados que no hubiese atendido a su fundamento constitutivo carecería de legitimidad y, por ende, de vinculariedad, pues como señala Ferrajoli -aunque haciendo más extensiva su afirmación- los derechos fundamentales en su carácter de tales son oponibles tanto a los intereses económicos y financieros, como al mercado.

Por último, la diferenciación que establece Ferrajoli entre los derechos fundamentales y los derechos patrimoniales da pie a reconocer que si bien existe un derecho humano (civil) a la propiedad que incluye los derechos a convertirse en propietario y a disponer de los bienes que son de nuestra propiedad, esto no implica de ninguna manera que el derecho a la propiedad sea ilimitado (de hecho ningún derecho lo es, pues todos están sujetos a limitaciones legítimas) ni que bajo su nombre puedan avasallarse otros derechos humanos, tal como lo ha hecho ver la Corte Interamericana de Derechos Humanos (CrIDH) al resolver los casos Saramaka vs. Suriname y Kichwa de Sarayaku vs. Ecuador, pues en ambos destacó que la protección del derecho a la propiedad no es absoluta ya que está sujeta a restricciones que deben cumplir con los siguientes requisitos: a) que hayan sido previamente establecidas por la ley; b) que sean necesarias; c) que sean proporcionales y d) que tengan el fin de lograr un objetivo legítimo en una sociedad democrática (CrIDH, 2007: 127). En tal sentido, respecto a la última de las restricciones indicadas, al analizar el conflicto entre propiedad privada y propiedad comunal, la Corte tomó en consideración para fallar a favor de estos pueblos indígenas el papel que juega la propiedad 
comunal para la subsistencia de los pueblos, así como los daños generados al medio ambiente, en el primer caso por la concesión a empresas madereras y, en el segundo, a empresas que llevaron a cabo actividades de exploración y explotación de petróleo crudo (CrIDH, 2007: 154; 2012: 156).

$\mathrm{El}$ ejercicio de interpretación de la $\mathrm{CrIDH}$, en perfil ferrajoliano, bien podría hacerse extensiva a amplios espectros temáticos del orden internacional, como las regulaciones en materia de propiedad intelectual y transferencia de tecnología, la tendencia a la mercantilización de la educación, la regulación de las tasas de interés (para poner freno a la usura), la precarización laboral y la detención de los gastos militares, entre otros.

Más allá de lo anterior, la interpretación de Ferrajoli apunta a que un constitucionalismo global conlleva el aseguramiento de los mínimos de subsistencia requeridos por las personas y a los valores de la igualdad, la democracia, la paz y la tutela del más débil como valores que fundamentan a los derechos fundamentales. Así, el orden internacional solamente cobra sentido y legitimidad si frente al poder, cualquiera que sea su tipo u orientación, ofrece una defensa radical, definitiva y efectiva contra la desigualdad y, por ende, contra una de las principales causas del avasallamiento de la dignidad humana en el mundo contemporáneo.

De esta forma Ferrajoli ofrece una propuesta que vincula algunos de los postulados básicos de la ética del desarrollo no sólo como obligaciones emanadas del derecho internacional, sino como el fundamento mismo del sistema.

En resumen, las propuestas de Piketty (2015) y Ferrajoli (1999; 2001) remiten, respectivamente, a la necesidad de controlar al capital y con ello retomar el control del capitalismo, a través de un impuesto progresivo y global, que idealmente debería ser universal; y, a repensar el fundamento del orden internacional que no descansa en una voluntad estatal ilimitada, sino en el cumplimiento de los derechos fundamentales; a marcar una clara distinción entre la calidad de los derechos fundamentales y de los derechos patrimoniales, así como tener muy presente la preeminencia de los primeros.

\section{NOTA FINAL}

No considero en absoluto fuera de lugar a las propuestas que apuntan a que la situación que enfrenta la humanidad de agotamiento, degradación o daño ambiental irreversible (Cante \& Ramírez, 2011); de enorme desigualdad económica y de la distribución de la riqueza; de desempleo estructural; y de retroceso en la protección y garantía de los derechos humanos, es de tal magnitud y complejidad que las medidas que debieran asu- 
mirse tendrían que ser más radicales, imponiendo límites racionales al crecimiento, al consumo y al despilfarro. Pero también entiendo que un gran reto ético es luchar contra la riqueza desmesurada y oligárquica que predomina hoy día, porque controlar al capital no se limita a una cuestión de riqueza, sino también al poder que ésta genera y que ha sido utilizado para influir en la orientación del sistema internacional en la era del capitalismo financiero (Canto \& Ramírez, 2011: 275), que no de forma exclusiva, pero si destacada, ha tendido a una mejor y más expedita protección de los intereses económicos y comerciales que de los derechos humanos y de los valores éticos involucrados en los procesos de desarrollo, atentando con ello contra las razones que le dieron origen y que, en última instancia, pueden justificar su existencia.

Comparto plenamente la idea de que el egoísmo como único motor de la conducta humana es insostenible (Martínez, 2007b; Sen, 2000), pero no puedo dejar de advertir que a lo largo de la historia se observa una tendencia por parte de grupos y personas en lo particular a acaparar bienes, riqueza o poder puesto que suponen el control y la manipulación del resto de las personas. Los tiempos que corren presentan una peculiaridad frente a momentos anteriores, ahora está en juego la misma viabilidad de la vida humana al estar en riesgo el planeta que la alberga. Por ello no es posible conformarse con medidas paliativas, se debe ir a la base de la problemática para poder guardar una esperanza razonable en un futuro posible, diferente al imaginado por Schopenhauer. De ahí que los principios que han emanado de la ética del desarrollo deban acompañarse de los medios que permitan su materialización, antes de que distopías más jóvenes nos alcancen.

\section{REFERENCIAS}

-Aguilera R. \& López, R. (2007). Los derechos fundamentales en la teoría jurídica garantista de Luigi Ferrajoli. Revista jurídica Iustitia, (17), 157-206.

-Alcalá, R. (2009). Democracia y relaciones interculturales. En-claves del Pensamiento, $\operatorname{III}(6), 75-90$.

-Allami, C. \& Cibils, A. (2010). Crisis financieras y regulación: propuestas heterodoxas. Politica y cultura, (34), 57-85.

-Alonzo, A. (2004). ATTAC Praxis México. El hermano radical de Latinoamérica. El Cotidiano, 19(125), 33-40.

-Amnístia Internacional (2017). Informe 2016/17. La situación de los derechos bumanos en el mundo. Londres: Amnístia Internacional.

-Archel, P., y Gómez, M. (2014). Crisis de la valoración contable en el capitalismo cognitivo. Revista Innovar, 24(52), 103-116.

-Aristóteles (1998). Ética nicomaquea (17 ed.). México: Porrúa. 
-Banco Mundial (2017). Ayuda Oficial al Desarrollo neta recibida (\% del INB). Recuperado de http://datos.bancomundial.org/indicador/DT.ODA.ODAT.GN.ZS?locations=US\&view $=$ chart.

-Bradbury, R. (2007). Fabrenheit 451. Barcelona: Random House Mondadori.

-Cante, F. \& Ramírez, V. (2011). Hacia un cambio radical en la lógica del desarrollo. Cuadernos de Economía, XXX(54), 253-280.

-Castrillón, A. (2016). ¿Se abrirán de nuevo las grandes alamedas? Luis Fernando Medina, El fénix rojo. Las oportunidades del socialismo. Revista de Economía Institucional, 18(34), 341-351.

-Concord AidWatch (2015). Looking to the future, don't forget the past. Bruxelles: European NGO confederation for relief and development.

-Conill, J. (2004). Horizontes de economía ética. Madrid: Tecnos.

-Cortina, A. (2011). Una propuesta de ética del desarrollo. Éthique et économique, 8(1), 8-24.

-CrIDH (2007). Caso del pueblo Saramaka vs. Suriname. Excepciones Preliminares, Fondo, Reparaciones y Costas. Sentencia de 28 de noviembre de 2007. Serie C No. 172.

-CrIDH (2012). Caso Pueblo Indígena Kichwa de Sarayaku vs. Ecuador. Fondo y reparaciones. Sentencia de 27 de junio de 2012. Serie C No. 245.

-Crocker (2007). Ética del desarrollo y globalización. En J. Jongitud (comp.), Ética del desarrollo y responsabilidad social en el contexto global (pp. 45-110). Xalapa: Universidad Veracruzana.

-Crocker, D. (2004). Development ethics: sources, agreements, and controversies. Avalaible: https://msu.edu/ phl/EandDWebsite/sources/Development_Ethics.pdf. Consulted: april 102017.

-Estefanía, J. (2016). Muerte lenta de la gobernanza económica. El País. 29 de septiembre de 2016 Recuperado de http://economia.elpais.com/economia/2016/09/23/actualidad/1474630435_357272.html.

-Ferrajoli, L. (1999). Derechos y garantías. La ley del más débil. Madrid: Trotta.

-Ferrajoli, L. (2001). Los fundamentos de los derechos fundamentales. Madrid: Trotta.

-Foro Económico Mundial (2017). The global risks report 2017 (12th edition). Geneva: World Economic Forum.

-Fukuyama, F. (1989). The end of history? The National Interest, (16), 3-18.

-Giraldi, M. (1995). Michel Albert, capitalismo contra capitalismo. Estudios latinoamericanos, (4), 245-247.

-Goulet, D. (1965). Ética del desarrollo. Barcelona: Iepala-Estela.

-Hevia, F. (2011). La difícil articulación entre políticas universales y programas focalizados. Etnografía institucional del programa Bolsa Familia de Brasil. Gestión y Política Pública, XX(2), 331-379.

-Hueso, V. (1998). Francis Fukuyama. El fin de la historia y el último hombre. Una visión optimista de la evolución de la historia. Cuadernos de estrategia, (99), 197-205.

-Huxley, A. (2002). Un mundo feliz ( $3^{\mathrm{a}}$ ed.). Barcelona: Plaza \& Janés editores.

-Jongitud, J. (2003). Teorías éticas del desarrollo: aproximación a cuatro de ellas. Revista Iberoamericana de autogestión y acción comunal, (41-43), 49-76. 
-Jongitud, J. (2008). El derecho al desarrollo en el ámbito de las Naciones Unidas. Notas criticas. Xalapa: Universidad Veracruzana.

-Jongitud, J. (2010). Derecho al desarrollo: estado del arte. Letras jurídicas, 11(21), 119-138.

-Llinares, J. (2017). La renta básica universal, cada vez menos una utopía, empieza a testearse en Europa. El economista. 7 de enero de 2017. Recuperado de http://www.eleconomista.es/economia/noticias/8068156/01/17/Larenta-basica-universal-cada-vez-menos-una-utopia-empieza-a-testarse-enEuropa.html.

-Maroto, J. (2014). La Ayuda Oficial al Desarrollo española en Guinea Ecuatorial: un análisis crítico. Cuadernos Geográficos, 53(1), 160-187

-Martínez, E. (2007a). Desarrollo como plena ciudadanía. En J. Jongitud (comp.), Ética del desarrollo y responsabilidad social en el contexto global (pp. 139-169). Xalapa: Universidad Veracruzana.

-Martínez, E. (2007b). Ética del desarrollo de los pueblos: panorámica y perspectivas. Diálogo filosófico, (69), 362-288.

-Martínez, E. (2013). Ética del desarrollo: superar la injusticia global. En B. Román y G. de Castro (eds.), Cambio social y cooperación en el siglo XXI. Vol. 2. El reto de la equidad dentro de los límites ecológicos (pp. 38-53). Barcelona: Icaria editorial.

-Marx, C. \& Engels F. (1985). Manifiesto del partido comunista ( $7^{a}$ edición). México: Editores Unidos Mexicanos.

-Meyer, L. (2004). La guerra fría en el mundo periférico: el caso del régimen autoritario mexicano. La utilidad del anticomunismo discreto. En D. Spenser (coord.), Espejos de la Guerra Fría: México, América Central y el Caribe (pp. 95117). México: Porrúa-CIESAS-SRE.

-Moro, O. (2006). La perspectiva genealógica de la historia. Santander: Universidad de Cantabria.

-Muñoz, Y. \& Torres, M. (2012). Análisis de la ayuda oficial al desarrollo para servicios sociales básicos en el siglo XXI. Estudios de Economía Aplicada, 30(3), 1023-1048.

-ONU (1970). Estrategia internacional del desarrollo para el segundo decenio de las Naciones Unidas para el desarrollo. Resolución 2626 (XV) de 24 de octubre de 1970.

-ONU (1974). Declaración sobre el establecimiento de un nuevo orden económico internacional. Resolución 3201 (S-VI) de 1 de mayo de 1974.

-ONU (1986). Declaración sobre el derecho al desarrollo. Resolución 41/128 del 4 de diciembre de 1986.

-Orwell, G. (2003). Rebelión en la granja ( $3^{\mathrm{a}}$ ed). México: Grupo Editorial Tomo.

-Orwell, G. (2017). 1984. México: Penguin Random House.

-Oxfam (2016). Informe de Oxfam. Una economía al servicio del 1\%. Acabar con los privilegios y la concentración de poder para frenar la desigualdad extrema. Recuperado de https://www.oxfam.org/sites/www.oxfam.org/files/file_attachments/bp210-economy-one-percent-tax-havens-180116es_0.pdf 
-Piketty, T. (2015). El capital en el siglo XXI (2a ed.). México: Fondo de Cultura Económica.

-Pleyers, G. (2003). Del barrio al globo: los niveles del movimiento para otra mundialización. Revista de Ciencias Sociales, II(100), 179-188.

-Pogge, T. (2013). Hacer justicia a la humanidad. México: UNAM-FCE-CNDH.

-Rodríguez, G; Ramos, J; \& Gómez, V. (2013). Explorando la Ayuda Oficial al Desarrollo: un análisis del debate desde la teoría económica neoinstitucional. Investigación \&o Desarrollo, 21(1), 108-129.

-Schopenhauer, A. (1998). El amor, las mujeres y la muerte ( $3^{\mathrm{a}}$ ed.). México: Porrúa.

-Sen, A. (1999). Sobre ética y economía. Madrid: Alianza Editorial.

-Sen, A. (2000). Desarrollo y libertad. Barcelona: Planeta.

-Social Watch (2007). Quinto informe anual de la plataforma 2015 y más. El perfil social del desarrollo. Situación y perspectiva de la lucha contra la pobreza mundial en 2007. Madrid: Icaria.

-Valek, G. (2000). La divulgación de la ciencia, reto para la comunicación y el periodismo. En J. Tonda, A. Ma Sánchez y N. Chávez (Coords.), Antología de la divulgación de la ciencia en México. México: UNAM.

-Valero, J. (2017). El futuro de la ‘tasa Tobin', en manos de Bélgica, Eslovaquia y Eslovenia. El Economista. 22 de marzo de 2017. Recuperado de http://www.eleconomista.es/economia/noticias/8238370/03/17/El-futuro-de-la-tasa-Tobin-en-manos-de-Belgica-Eslovaquia-y-Eslovenia.html.

-Vidal, X. (2014a). Piketty: "Un impuesto global al capital no debe esperar a un gobierno mundial" (entrevista). El País. 15 de octubre de 2014. Recuperado de http://economia.elpais.com/economia/2014/10/15/actualidad/1413401969_753425.html.

-Vidal, X. (2014b). Zarpazos a la tasa Tobin. El país. 16 de mayo de 2014. Recuperado de http://economia.elpais.com/economia/2014/05/07/actualidad/1399492001_722841.html.

Sumario: 1. Nota preliminar; 2. Estado del arte respecto a la ética del desarrollo: los consensos; 3. Medidas para alcanzar los postulados de la ética del desarrollo; 4. El capital en el siglo XXI, Thomas Piketty; 5. Los derechos fundamentales, Luigi Ferrajoli; 6. Controlar al capital, limitar la propiedad; 7. Nota final; Referencias. 